\title{
Morphological and molecular characterization of Thamnocalamus spathiflorus subsp. spathiflorus at population level
}

\author{
Samik Bhattacharya $\cdot$ Jayadri Sekhar Ghosh ·
}

Malay Das · Amita Pal

Published online: 29 July 2009

(C) Springer-Verlag 2009

Erratum to: Plant Syst Evol (2009)

DOI 10.1007/s00606-008-0092-1

In the published original article, the following information should be read along with the legend of Fig. 5:

DNA ladder markers $(M)$ lanes and samples in lanes 1-9 in both part figures $\mathbf{a}$ and $\mathbf{b}$ were run separately under similar gel electrophoresis conditions and were later put together using tools of Adobe Photoshop CS2.

The online version of the original article can be found under doi:10.1007/s00606-008-0092-1.

S. Bhattacharya $\cdot$ J. S. Ghosh · A. Pal ( $\)$

Plant Molecular and Cellular Genetics Section, Bose Institute,

P 1/12 CIT Scheme VIIM, Kolkata 700054, India

e-mail: amita@bic.boseinst.ernet.in

M. Das

Department of Plant Pathology, Physiology and Weed Science, Virginia Polytechnic Institute and State University, Blacksburg, VA 24061, USA 